\title{
Spinal Cord Stimulators: an Introduction
}

\author{
Steven Falowski MD \\ Thomas Jefferson University
}

Follow this and additional works at: https://jdc.jefferson.edu/jhnj

Part of the Neurology Commons

Let us know how access to this document benefits you

\section{Recommended Citation}

Falowski MD, Steven (2008) "Spinal Cord Stimulators: an Introduction," JHN Journal: Vol. 4 : Iss. 2 , Article 6.

DOI: https://doi.org/10.29046/JHNJ.004.2.002

Available at: https://jdc.jefferson.edu/jhnj/vol4/iss2/6

This Article is brought to you for free and open access by the Jefferson Digital Commons. The Jefferson Digital Commons is a service of Thomas Jefferson University's Center for Teaching and Learning (CTL). The Commons is a showcase for Jefferson books and journals, peer-reviewed scholarly publications, unique historical collections from the University archives, and teaching tools. The Jefferson Digital Commons allows researchers and interested readers anywhere in the world to learn about and keep up to date with Jefferson scholarship. This article has been accepted for inclusion in JHN Journal by an authorized administrator of the Jefferson Digital Commons. For more information, please contact: JeffersonDigitalCommons@jefferson.edu. 


\section{Spinal Cord Stimulators: an Introduction}

\section{Steven Falowski, MD \\ Department of Neurological Surgery, Thomas Jefferson University, Philadelphia, Pennsylvania}

\section{Background}

Pain can be divided into two broad categories, nociceptive pain and neuropathic pain. Nociceptive pain is a dull, throbbing pain which results from irritated nerves after physical tissue injury. This is seen commonly in cancer or after a fracture. Nociceptive pain is amenable to treatment with pain medications such as opioids and/or anti-inflammatories. Neuropathic pain is described as burning, shooting, or shocking pain. This type of pain results from nerve damage or abnormal nerve conduction such as pain exhibited with failed back syndrome, post surgical pain, neuromas, shingles, and complex regional pain syndrome (previously called RSD or causalgia). Neuropathic pain tends to be resistant to treatment with pain medications. Neurostimulation has been an effective treatment option for the management of chronic neuropathic pain. It is a reversible therapy which can even be tested before permanent implantation.

Spinal cord stimulation (SCS) is an adjustable, non-destructive, neuromodulatory procedure which delivers therapeutic doses of electrical current to the spinal cord or to a targeted nerve. This lowvoltage stimulation can block the transmission of pain. The enthusiasm for SCS began with the introduction of the gate control theory for pain control by Melzack and Wall in $1965^{1}$. They noted that stimulation of large myelinated fibers of peripheral nerves resulted in paresthesias and blocked the activity in small nociceptive projections. In other words, pain receptors compete with each other and with other sensory afferents. Appropriate stimulation of a "rival" afferent can effectively block a pain signal. This is why rubbing your chin after its been hit relieves the pain - the bump is still present, but the rubbing blocks it. The SCS system is implanted in a space surrounding the spinal cord, called the epidural space, where it stimulates the dorsal columns which can mask the sensation of pain by producing a tingling sensation.

\section{Patient Selection}

Some of the criteria listed below can be used to determine candidates for neurostimulation:

- Conservative therapies have failed to adequately help the pain.

- Further traditional surgical intervention is not indicated.

- No serious untreated drug habituation for the pain condition exists.

- Psychological evaluation and clearance for implantation have been received, sorting out untreated depression or anxiety, addiction, or other behavioral disorders.

- No medical issues exist that would present problems with doing the surgery.

\section{Indications}

The most common indications include post-laminectomy syndrome or failed back surgery syndrome (FBSS), complex regional pain syndrome (CRPS) or reflex sympathetic dystrophy (RSD), ischemic limb pain, and angina. Scattered reports regarding the treatment of intractable pain due to other causes including visceral/abdominal pain, cervical neuritis pain, spinal cord injury pain, post-herpetic neuralgia, and neurogenic thoracic outlet syndrome have also appeared in the literature.

\section{Surgical Technique}

The procedures are most commonly performed by neurosurgeons or anesthesiologists specializing in pain management ${ }^{2-5}$. A lead is temporarily utilized to cover a wide area for pain control. The lead, or electrode, is implanted into the epidural space. The lead is attached to a power source called the pulse generator (or commonly known as the battery). This is then connected to an outside or external system which is held in place by sterile dressings. The unit is then tested for efficacy during a screening period, which is usually $3-10$ days.

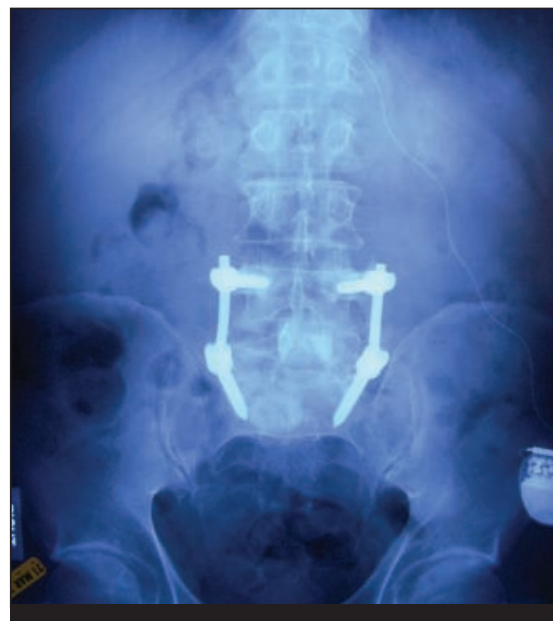

Figure 1

A patient that had persistent neuropathic pain in his back and his legs despite anterior and posterior spinal reconstructive surgery.

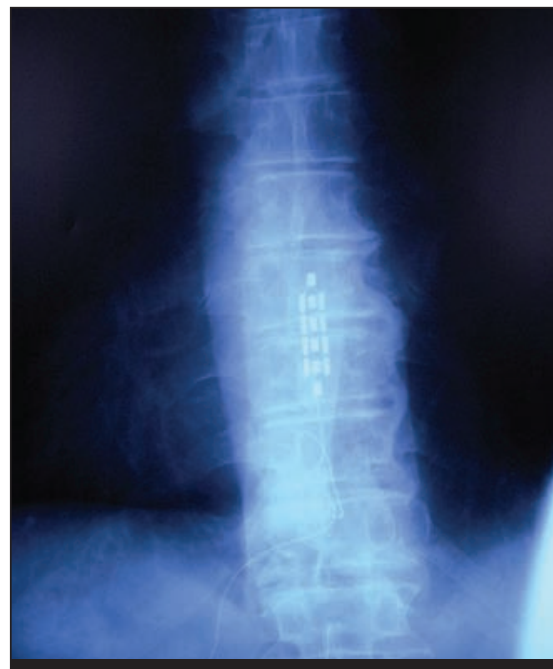

Figure 2

The patient received an implanted transverse tripole electrode in the thoracic spine. The new electrode has the ability of focusing the electrical field into the dorsal column to maximize the paresthesia into the back while avoiding painful stimulation of the nerves into the ribs. 
If relief is obtained at this point, the system may be implanted permanently. The stimulator is usually placed in an area where the skin will not be irritated and the unit will not be pressing against bone. The abdomen and buttocks are common locations.

\section{Benefits}

Neurostimulation has been shown to have a $50 \%$ improvement in pain relief, reduce the use of medications, and allow the person experience an improvement in their quality of life ${ }^{6-7}$. These benefits are expected to increase with improvements in the technology and in understanding of how pain signals are generated and gated in the nervous system. It is important to realize that neurostimulation is a treatment option along the continuum of pain control.

\section{Potential Adverse Effects}

Surgical risks associated with an implant include hematoma, infection, and possible leakage of cerebrospinal fluid. Because this is a device, there can be malfunction of the hardware or can have disruption in the settings by other signals; for example, patients with an SCS are advised to turn it off before going through an anti-theft device in a retail store; additionally, patients with an SCS can not undergo a magnetic resonance imaging (MRI) scan.

\section{Summary}

Spinal cord stimulation therapy has been available and approved for over two decades. In the last five years, there have been significant advances in the technology: smaller, rechargeable batteries; better electrodes; and improved implantation techniques. More physicians are adapting this therapy in their practice for pain management and we are effectively improving patients' lives.

The treatment of chronic pain remains challenging. Experience in the technique and the equipment has made SCS a much more reliable and safe modality. Like all the modalities performed for chronic pain management, its results are favorable. It is important to remember that the goal of neurostimulation is to reduce pain, rather than to eliminate pain. Very few other invasive modalities can claim this success rate with a few years of follow-up. Spinal cord stimulation has earned a well established and firm role in contemporary chronic pain management.

Further information is available at the Neural Interfaces Program Website of the NIH, http:// www.ninds.nih.gov/funding/research/npp/

\section{References}

1. Melzack R, Wall PD. Pain mechanisms: a new theory. Science 1965;150:971-9.

Devulder J, De Colvenaer L, Rolly G, et al. Spinal cord stimulation in chronic pain therapy. Clin J Pain 1990;6:51-6.

2. Devulder J, Vermeulen H, De Colvenaer L, et al. Spinal cord stimulation in chronic pain: evaluation of results, complications, and technical considerations in sixty-nine patients. Clin J Pain 1991;7:21-8.

3. Racz GB, McCarron RF, Talboys P. Percutaneous dorsal column stimulator for chronic pain control. Spine 1989;14:1-4.

4. Falowski S, Celii A, Sharan A. Spinal cord stimulation: an update. Neurotherapeutics. 2008 Jan;5(1):86-99.

5. Turner JA, Loeser JD, Bell KG. Spinal cord stimulation for chronic low back pain: a systematic literature synthesis. Neurosurgery 1995;37:1088-95; discussion 95-6.

6. Burchiel KJ, Anderson VC, Brown FD, et al. Prospective, multicenter study of spinal cord stimulation for relief of chronic back and extremity pain. Spine 1996;21:2786-94. 